eCommons@AKU

\title{
Furazolidone, Co-amoxiclav, Colloidal Bismuth Subcitrate, and Esomeprazole for patients who failed to eradicate Helicobacter pylori with triple therapy
}

\section{Z Abbas}

Aga Khan University, zaigham.abbas@aku.edu

Javed Yakoob

Aga Khan University, javed.yakoob@aku.edu

Shahab Abid

Aga Khan University, shahab.abid@aku.edu

Wasim Jafri

Aga Khan University, wasim.jafri@aku.edu

Muhammad Islam

Aga Khan University

See next page for additional authors

Follow this and additional works at: https://ecommons.aku.edu/pakistan_fhs_mc_med_med

Part of the Gastroenterology Commons

\section{Recommended Citation}

Abbas, Z., Yakoob, J., Abid, S., Jafri, W., Islam, M., Azam, Z., Hilal, I. (2009). Furazolidone, Co-amoxiclav, Colloidal Bismuth Subcitrate, and Esomeprazole for patients who failed to eradicate Helicobacter pylori with triple therapy. Digestive Diseases and Sciences, 54(9), 1953-1957.

Available at: https://ecommons.aku.edu/pakistan_fhs_mc_med_med/154 
Authors

Z Abbas, Javed Yakoob, Shahab Abid, Wasim Jafri, Muhammad Islam, Zahid Azam, and Imran Hilal 


\title{
Furazolidone, Co-amoxiclav, Colloidal Bismuth Subcitrate, and Esomeprazole for Patients Who Failed to Eradicate Helicobacter pylori with Triple Therapy
}

\author{
Zaigham Abbas · Javed Yakoob · Shahab Abid • \\ Wasim Jafri · Muhammad Islam · Zahid Azam • \\ Imran Hilal
}

Received: 22 July 2008/ Accepted: 13 October 2008/Published online: 5 December 2008

(C) Springer Science+Business Media, LLC 2008

\begin{abstract}
There is increasing evidence of Helicobacter pylori $(H$. pylori) resistance to the classical triple therapy consisting of a proton-pump inhibitor and clarithromycin with either amoxicillin or metronidazole. This study is aimed at establishing the efficacy and safety of a 14-day regimen to eradicate $H$. pylori in patients who have failed with the classical triple therapy given for 14 days. One hundred seventy-six patients diagnosed to have $H$. pylori infection were given triple therapy for 14 days. Fifty-two patients who failed to respond as evident from positive 14C-urea breath test (UBT) done 4-6 weeks after the completion of triple therapy were offered a combination regimen comprised of furazolidone $200 \mathrm{mg}$ b.i.d, co-amoxiclav $1 \mathrm{~g}$ b.i.d., colloidal bismuth subcitrate $240 \mathrm{mg}$ b.i.d., and esomeprazole $40 \mathrm{mg}$ b.i.d. for 14 days. The mean age of these patients was $41 \pm 13$ years (range 2067). Thirty-four were males. To document eradication of $H$. pylori, UBT was repeated 4 weeks after the completion of treatment. On an intention-to-treat analysis, the eradication rate was $81 \%$ (42 out of 52) whereas on per-protocol basis, the eradication rate was $82.4 \%$ (42 out of 51). In conclusion, this new regimen represents a suitable second-line therapy.
\end{abstract}

Keywords Helicobacter pylori - Clarithromycin . Furazolidone $\cdot$ Co-amoxiclav $\cdot$ Bismuth $\cdot$ Esomeprazole

This study was conducted under ClinicalTrials.gov number NCT00520949.

Z. Abbas $(\bowtie) \cdot$ J. Yakoob · S. Abid · W. Jafri · M. Islam ·

Z. Azam - I. Hilal

Department of Medicine, The Aga Khan University, Stadium

Road, P.O. Box 3500, Karachi 74800, Pakistan

e-mail: zaigham@akunet.org

\section{Introduction}

Triple therapy, a combination of proton-pump inhibitor (PPI) with two antibiotics, remains the recommended first choice anti-Helicobacter pylori (H. pylori) treatment. The usual antibiotics used are clarithromycin and amoxicillin or metronidazole [1]. However, there is an increasing evidence of $H$. pylori resistance to classical triple therapy [2-5]. Increasing resistance to clarithromycin and metronidazole is being documented as leading to failure of standard eradication regimes [3, 4]. Amoxicillin-resistant H. pylori have also been reported [5]. Another reason for failure is low patient compliance with this treatment due to side effects [6]. Clarithromycin, metronidazole, and amoxicillin used in therapy may cause several side effects such as nausea, vomiting, metallic taste in the mouth, diarrhea, headache, dizziness, and yeast infections in women. A regimen useful in one geographical area may not be effective or practical in another area. Bismuthcontaining quadruple therapy with a PPI, bismuth subcitrate, metronidazole, and tetracycline given for 2 weeks may be a first choice treatment option in an era of increased clarithromycin resistance $[1,2]$. The best first-line and retreatment regimens have yet to be established.

It has been reported that the amoxicillin-clavulanate combination has a higher activity than amoxicillin alone against $H$. pylori $[5,7]$. Furazolidone has also been used in the first-line and rescue regimens [8, 9]. It is an antimicrobial agent that is both available and inexpensive in developing countries. It has been used in China for more than 20 years in the treatment of peptic ulcer as the single therapeutic agent, with healing rates comparable to those obtained with cimetidine and displaying lower recidivating rates [10]. The combination therapy with furazolidone, amoxicillin-clavulanate (co-amoxiclav), bismuth compound, and a PPI may 
represent an effective therapeutic scheme for the treatment of resistant $H$. pylori infection. It is expected to be better tolerated than clarithromycin-based regimens and effective in the re-treatment for $H$. pylori infection. This study was aimed at establishing the efficacy and safety of a 14-day regimen using the above drugs to eradicate $H$. pylori in patients who have failed with the classical triple therapy given for 14 days.

\section{Materials and Methods}

Patients

In this prospective, open study, performed between October 2006 and May 2008, we enrolled 176 patients from our gastroenterology clinic who were diagnosed with $H$. pylori infection and had associated endoscopic gastritis, peptic ulcer, or gastroesophageal reflux disease. Informed written consent was obtained from each patient before entering the trial. Exclusion criteria were evidence of any malignancy, gastric outlet syndrome, history of gastric surgery, chronic liver disease, severe chronic renal failure, or any major comorbidity, and known or suspected hypersensitivity to the medication used in the study. Complete history was taken including present and past history of illness, medications, smoking, and alcohol intake. Physical examination was also performed. Hematological and biochemical tests including complete blood count, blood urea nitrogen, serum creatinine, and liver function tests were carried out. Diagnosis of $H$. pylori infection was made on the basis of any two out of three positive tests, i.e., 14C-urea breath test (UBT), rapid urease test, or histology on gastric biopsies obtained at endoscopy, two each from both antrum and body. UBT was done with the Heliprobe System (Noster $\mathrm{AB}$, Sweden) and read as described by the manufacturer: 0 - patient not infected, I-borderline result, II-patient infected [11]. For the rapid urease test, Pronto Dry (Medical Instrument Corp., France) was used with two biopsies, one each from the antrum and corpus and read at $30 \mathrm{~min}$ [12]. Hematoxylin and eosin stain was used for the detection of H. pylori. In doubtful cases Giemsa staining was carried out to ascertain presence of $H$. pylori. These patients were given a classical triple regimen of amoxicillin $1 \mathrm{~g}$, clarithromycin $500 \mathrm{mg}$, and omeprazole $20 \mathrm{mg}$ twice a day for 14 days. Eradication of $H$. pylori was documented by repeat UBT performed 4 weeks after completion of therapy. Patients who failed to eradicate $H$. pylori were recruited for a new combination protocol $(n=52)$. This furazolidone and bismuth-based regimen was comprised of co-amoxiclav (Augmentin, GSK) $1 \mathrm{~g}$ b.i.d., furazolidone (Furoxone, GSK) $200 \mathrm{mg}$ b.i.d., colloidal bismuth subcitrate (Cebes-S, Adamjee) $240 \mathrm{mg}$
H. pylori Infection

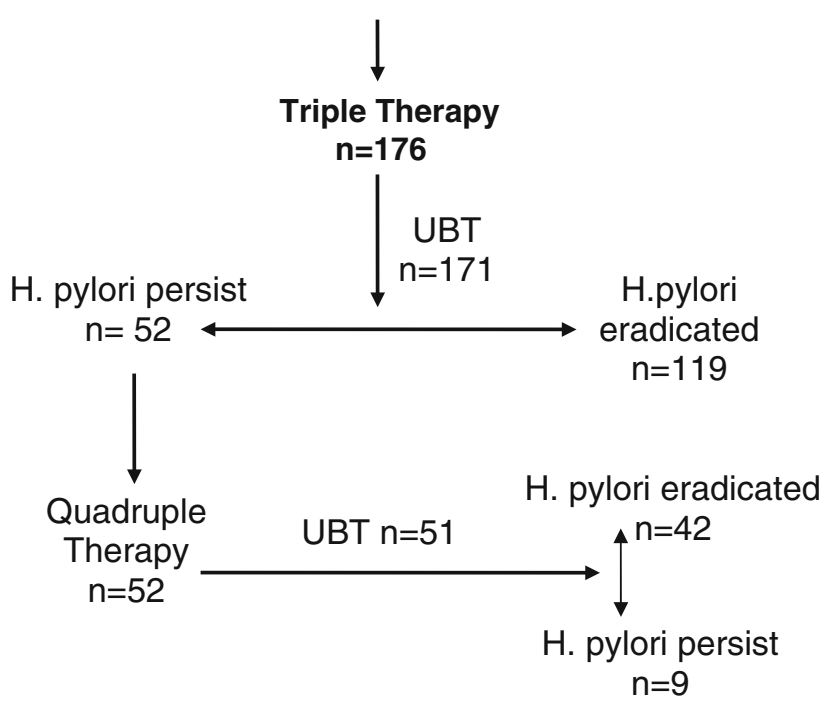

Fig. 1 Summary of the study

b.i.d., and PPI esomeprazole (Nexum, Getz Pharma) $40 \mathrm{mg}$ b.i.d. for 14 days. All patients were evaluated at the end of treatment for compliance with drugs and related adverse effects during the treatment. To improve the compliance all patients were warned of possible side effects beforehand. Therapeutic success was again evaluated by UBT 4 weeks after the completion of treatment (Fig. 1). The study was approved by the ethics committee of the hospital.

\section{Statistical Analysis}

Statistical calculations were performed with the SPSS statistics software, version 10.0 (SPSS Inc., Chicago, USA). Results were presented as mean \pm standard deviation for quantitative variables and numbers and percentages for qualitative variables. All patients were evaluated in an intention-to-treat (ITT) analysis, in which patients without final $H$. pylori determination or with protocol violations were considered treatment failures. The per-protocol (PP) analysis included all subjects who took at least $80 \%$ of each study medication as prescribed and completed the final $H$. pylori status assessment.

\section{Sample Size}

Assuming 90\% effectiveness for eradication of $H$. pylori infection in the study population with $95 \%$ confidence level and a bound on error of $\pm 8.5 \%$, the estimated sample size was 48 subjects for quadruple therapy; however, for standard triple therapy the response rate for eradication of $H$. pylori infection was expected to be $75 \%$, thus we took three times that amount for quadruple therapy, i.e., 144 subjects. 


\section{Results}

One hundred seventy-six patients were enrolled for triple therapy over a period of 20 months. In ITT analysis, eradication was achieved in $119(68 \%)$ patients. In 52 patients who failed to respond, the new combination therapy as described above was commenced. The mean age of patients who received this therapy was $41 \pm 13$ years (range 20-67). Thirty-four were males with male to female ratio of $2: 1$.

\section{Efficacy}

All patients completed the study with one exemption where follow-up UBT could not be done. $H$. pylori eradication was achieved in $42(81 \%)$ out of 52 by ITT analysis and 42 of $51(82.4 \%)$ by PP analysis (Table 1). The mean age of our patients receiving both triple and furazolidone-based therapy was only 41 years. The failure of triple therapy was present in $34 \%$ of the patients between 31 and 50 years of age $(P=0.05)$. However, in the same age group, new combination therapy failed in $26 \%$ of the patients, which is not different from other age groups $(P=0.33)$.

\section{Safety}

The most frequent side effects were nausea and metallic taste in the mouth experienced by $26(50 \%)$ and $11(21 \%)$ patients, respectively (Table 2 ). However, side effects were mild and well tolerated.

Table 1 Characteristics of the study patients receiving new secondline combination

\begin{tabular}{ll}
\hline Description & Value \\
\hline Total patients & 52 \\
Age (mean \pm SD) & $41 \pm 13$ \\
Gender (M:F), number (\%) & $33(65 \%): 19(35 \%)$ \\
Endoscopic findings, number (\%) & \\
$\quad$ Gastritis & $47(90 \%)$ \\
$\quad$ Gastroesophageal reflux disease & $4(8 \%)$ \\
$\quad$ Peptic ulcer & $1(2 \%)$ \\
14C-UBT post-triple therapy, number $(\%)$ & \\
$\quad$ Positive & $9(17 \%)$ \\
$\quad$ Negative & $42(81 \%)$ \\
$\quad$ Not done & $1(2 \%)$ \\
Eradication rate, number $(\%)$ & \\
ITT & $42(81 \%)$ \\
PP & $43(83 \%)$ \\
\hline
\end{tabular}

UBT 14C-urea breath test, ITT intention-to-treat, $P P$ per-protocol
Table 2 Side effects of the second-line therapy $(n=52)$

\begin{tabular}{ll}
\hline Side effect & Number of patients $(\%)$ \\
\hline Nausea & $26(50 \%)$ \\
Dark stool & $26(50 \%)$ \\
Heart burn & $5(10 \%)$ \\
Metallic taste in the mouth & $11(21 \%)$ \\
Reduced appetite & $2(4 \%)$ \\
Weakness & $1(2 \%)$ \\
\hline
\end{tabular}

\section{Discussion}

$H$. pylori infection is the main cause of gastritis, gastroduodenal ulcer, and gastric cancer and is considered a major public health issue. Factors influencing success or failure of an anti- $H$. pylori regimen include patient's compliance, antimicrobial resistance, and duration of therapy [2]. The most effective recommended regimen, i.e., a PPI with two antimicrobials such as amoxicillin, clarithromycin, or metronidazole, fails to eradicate infection in more than $20 \%$ of the compliant patients [2, 13, 14]. Therefore, appropriate selection of the patients and choice of antibiotics are of major importance for the treatment outcome [15, 16]. Third world countries have large populations with low socioeconomic levels and high bacterial resistance to antibiotics. However, the incidence of clarithromycin-resistant strains of $H$. pylori is increasing throughout the world [17, 18]. We have previously reported high prevalence of clarithromycin resistance among our patients with $H$. pylori infection [19].

In a previous multicenter study done in patients with documented active duodenal ulcer, 1-week triple therapy with PPI, amoxicillin, and clarithromycin gave an eradication rate of $62 \%$ with ITT analysis in a group of patients recruited from Pakistan [20]. In our study, we had a $32 \%$ failure rate of triple therapy to eradicate $H$. pylori infection despite giving it for 2 weeks. The low eradication rate might be attributed to several factors including the majority of patients having non-ulcer dyspepsia, comparatively younger age group, and antibiotic resistance. A previous study has described a higher resistance to clarithromycin in non-ulcer dyspeptic patients in comparison to duodenal ulcer patients [21]. Macrolides and amoxicillin are commonly prescribed in the community practice for various conditions including the treatment of upper and lower respiratory tract infection. It is known that the macrolide group of antibiotics display cross-resistance. The practice of self-prescription of medications in the community for minor ailments also contributed to resistance [22]. The mean age of our patients receiving both triple and new combination 
therapy was only 41 years. The failure rate of triple therapy was $34 \%$ of the patients between 31 and 50 years of age $(P<0.05)$. This is consistent with a previous study showing an increase bacterial load associated with younger age group is not easily eradicated [15]. However, in the same age group, new combination second-line therapy was more effective, as it failed in $26 \%$ of patients $(P=0.33)$.

On an ITT basis, the eradication rate with our combination therapy of furazolidone, colloidal bismuth subcitrate, and co-amoxiclav with PPI achieved a higher $H$. pylori eradication rate of $81 \%$ by ITT analysis and $83 \%$ by PP analysis. The regimen was useful as second-line therapy in our patients with high rate of triple therapy failure. We used co-amoxiclav instead of amoxicillin, which was already used in these patients when given triple therapy. Moreover, co-amoxiclav is superior to amoxicillin in eradicating $H$. pylori as it contains clavulanate potassium which binds to bacterial beta-lactamases and prevents break down of the amoxicillin molecule by bacteria that would otherwise be resistant to it [5, 7]. The other drug chosen in this regimen was furazolidone, which has been used to treat peptic ulcer disease in China $[10,23]$. The efficacy of furazolidone in the treatment of peptic ulcer disease is mainly due to its antibacterial activity against $H$. pylori [24]. Furazolidone has been shown to be an efficient component of first- and second-line and rescue therapies. Buzas and Jozan [25] have reviewed the efficacy of furazolidone-based therapies. Primary quadruple regimens containing furazolidone were superior to triple therapies with $83.5 \%$ eradication rate. Second-line schedules containing furazolidone obtained an eradication rate of $76.1 \%$. The third drug used in our combination was a bismuth compound, which does not have any resistance problem. Treatment was given for 14 days based on the results of the review suggesting the 'longer the better' $[2,25]$. PPI was also given twice a day to increase the local $\mathrm{pH}$ in the microenvironment surrounding $H$. pylori to prevent phenotypic resistance [26]. The side effects associated with new combination therapy were mild and well tolerated. Adherence was good due to the low side effect profile and well-motivated patients. This is in agreement with a metaanalysis that showed the frequency of adverse effects for furazolidone-based quadruple therapies was similar to standard triple therapies [27].

In conclusion, the new regimen with furazolidone, coamoxiclav, bismuth compound, and PPI represent an effective therapeutic scheme for the treatment of triple therapy resistant $H$. pylori infection. It is reasonably welltolerated and is an effective second-line regimen for the retreatment of $H$. pylori infection. Higher efficacy of this regimen is expected if used as a primary therapy.

\section{References}

1. Malfertheiner P, Megraud F, O'Morain C, et al. Current concepts in the management of Helicobacter pylori infection: the Maastricht III Consensus Report. Gut. 2007;56:772-781. doi:10.1136/ gut.2006.101634.

2. Graham DY, Shiotani A. New concepts of resistance in the treatment of Helicobacter pylori infections. Nat Clin Pract Gastroenterol Hepatol. 2008;5:321-331. doi:10.1038/ncpgas thep1138.

3. Mendonça S, Ecclissato C, Sartori MS, et al. Prevalence of Helicobacter pylori resistance to metronidazole, clarithromycin, amoxicillin, tetracycline and furazolidone in Brazil. Helicobacter. 2000;5:79-83. doi:10.1046/j.1523-5378.2000.00011.x.

4. Osato MS, Reddy R, Reddy SG, Penland RL, Malaty HM, Graham DY. Pattern of primary resistance of Helicobacter pylori to metronidazole or clarithromycin in the United States. Arch Intern Med. 2001;161:1217-1220. doi:10.1001/archinte.161. 9.1217.

5. Dore MP, Graham DY, Sepulveda AR, Realdi G, Osato MS. Sensitivity of amoxicillin-resistant Helicobacter pylori to other penicillins. Antimicrob Agents Chemother. 1999;43:1803-1804.

6. Kwok A, Lam T, Katelaris P, Leong RW. Helicobacter pylori eradication therapy: indications, efficacy and safety. Expert Opin Drug Saf. 2008;7:271-281. doi:10.1517/14740338.7.3.271.

7. Ojetti V, Migneco A, Zocco MA, Nista EC, Gasbarrini G, Gasbarrini A. Beta-lactamase inhibitor enhances Helicobacter pylori eradication rate. J Intern Med. 2004;255:125-129. doi:10.1046/ j.0954-6820.2003.01239.x.

8. Frota LC, da Cunha Mdo P, Luz CR, de Araujo-Filho AH, Frota LA, Braga LL. Helicobacter pylori eradication using tetracycline and furazolidone versus amoxicillin and azithromycin in lansoprazole based triple therapy: an open randomized clinical trial. Arq Gastroenterol. 2005;42:111-115. doi:10.1590/S000428032005000200009.

9. Eisig JN, Silva FM, Rodriguez TN, Hashimoto CL, Barbuti RC. A furazolidone-based quadruple therapy for Helicobacter pylori retreatment in patients with peptic ulcer disease. Clinics. 2005;60:485-488. doi:10.1590/S1807-59322005000600010.

10. Zheng ZT, Wang YB. Treatment of peptic ulcer disease with furazolidone. J Gastroenterol Hepatol. 1992;7:533-537. doi: 10.1111/j.1440-1746.1992.tb01034.x.

11. Hegedus O, Rydén J, Rehnberg AS, Nilsson S, Hellström PM. Validated accuracy of a novel urea breath test for rapid Helicobacter pylori detection and in-office analysis. Eur $J$ Gastroenterol Hepatol. 2002;14:513-520. doi:10.1097/000427 37-200205000-00008.

12. Said RM, Cheah PL, Chin SC, Goh KL. Evaluation of a new biopsy urease test: Pronto Dry for the diagnosis of Helicobacter pylori infection. Eur J Gastroenterol Hepatol. 2004;16:195-199. doi:10.1097/00042737-200402000-00012.

13. Bytzer P, O'Morain CM. Treatment of Helicobacter pylori. Helicobacter. 2005;10:40-46. doi:10.1111/j.1523-5378.2005. 00333.x.

14. Calvet X. Helicobacter pylori infection: treatment options. Digestion. 2006;73(Suppl 1):119-128. doi:10.1159/000089787.

15. Broutet N, Tschamgoué S, Pereira E, Lamouliatte H, Salamon R, Mégraud F. Risk factors for failure of Helicobacter pylori therapy-results of an individual data analysis of 2751 patients. Aliment Pharmacol Ther. 2003;17:99-109. doi:10.1046/j.13652036.2003.01396.x.

16. Mégraud F. Basis for the management of drug-resistant Helicobacter pylori infection. Drugs. 2004;64:1893-1904. doi:10.2165/ 00003495-200464170-00003. 
17. Megraud F. Helicobacter pylori and antibiotic resistance. Gut. 2007;56:1502. doi:10.1136/gut.2007.132514.

18. Egan BJ, Marzio L, O'Connor H, O'Morain C. Treatment of Helicobacter pylori infection. Helicobacter. 2008;13(Suppl 1):35-40. doi:10.1111/j.1523-5378.2008.00639.x.

19. Abid S, Yakoob J, Jafri W, Abbas Z, Mumtaz K. High prevalence of Clarithromycin resistance among patients with Helicobacter pylori infection: a study from a tertiary care center in Pakistan. Helicobacter. 2006;11(Suppl 2):A39. doi:10.1111/j.0083-8703. 2006.00375.x.

20. Wong BC, Chang FY, Abid S, et al. Triple therapy with clarithromycin, omeprazole, and amoxicillin for eradication of Helicobacter pylori in duodenal ulcer patients in Asia and Africa. Aliment Pharmacol Ther. 2000;14:1529-1535. doi:10.1046/j. 1365-2036.2000.00863.x.

21. van Doorn LJ, Schneeberger PM, Nouhan N, Plaisier AP, Quint WG, de Boer WA. Importance of Helicobacter pylori cagA and vacA status for the efficacy of antibiotic treatment. Gut. 2000;46:321-326. doi:10.1136/gut.46.3.321.
22. Sturm AW, van der Pol R, Smits AJ, et al. Over-the-counter availability of antimicrobial agents, self-medication and patterns of resistance in Karachi, Pakistan. J Antimicrob Chemother. 1997;39:543-547. doi:10.1093/jac/39.4.543.

23. Zheng ZT, Wang ZY, Chu YX, et al. Double-blind short-term trial of furazolidone in peptic ulcer. Lancet. 1985;1(8436):1048-1049.

24. Treiber G, Ammon S, Malfertheiner P, Klotz U. Impact of furazolidone-based quadruple therapy for eradication of Helicobacter pylori after previous treatment failures. Helicobacter. 2002;7:225-231. doi:10.1046/j.1523-5378.2002.00087.x.

25. Buzás GM, Józan J. Nitrofuran-based regimens for the eradication of Helicobacter pylori infection. J Gastroenterol Hepatol. 2007;22:1571-1581. doi:10.1111/j.1440-1746.2007.05082.x.

26. Scott D, Weeks D, Melchers K, Sachs G. The life and death of Helicobacter pylori. Gut. 1998;43(Suppl 1):S56-S60.

27. Fischbach LA, van Zanten S, Dickason J. Meta-analysis: the efficacy, adverse events, and adherence related to first-line antiHelicobacter pylori quadruple therapies. Aliment Pharmacol Ther. 2004;20:1071-1082. doi:10.1111/j.1365-2036.2004.02248.x. 